\title{
Gender and Religion: A Volatile Mixture
}

\author{
MORNY JOY \\ University of Calgary
}

\begin{abstract}
In recent years the term "gender" has been used with many different meanings as well as in applications that are far from consistent. Is this diversity an indication that the term should be abandoned because of such imprecision, or can certain currents or purposes, however illdefined, still be discerned? This paper is an investigation of contemporary usages of the term "gender" and the implications that could result for women involved in the study of religion.
\end{abstract}

Keywords: gender, religion, religious studies.

The term "gender", which is one of the principal themes of this conference: "Gender, Religion and Theory in Dialogue", has become somewhat ubiquitous in recent times. In fact, when I searched the Internet to obtain further information, I found at least thirty titles published in the past five years in connection with women and Religious Studies. As a result, I thought that I should first familiarize myself with its diverse usages before I wrote my paper. This was not an easy task to accomplish in a short time. In fact, the investigation was so wide-ranging and time-consuming, that I decided that "gender" as a concept, and its specific applications within Religious Studies, would become the main focus of this essay. My basic plan is to ground these explorations in as many concrete examples as I can find. Before beginning, however, I would like to make one qualification, and that is, I have become 
aware that the English term "gender", even from its grammatical perspective, is not available in many languages, e.g., it does not exist in Finnish. Thus, the word "gender" is usually transliterated, i.e., the English term is employed without any translation (Li 2004, 89-102). It is not my intention, however, to get involved in a lengthy discussion about such linguistic technicalities. Instead, what I want to stress is the actual occurrences of the word "gender", i.e., what people have meant when they employ the term. I then propose to consider the manner in which the term has been, or can be utilized in neutral, critical or manipulative ways. Finally, I will evaluate the results of this analysis, particularly with reference to the insights it can provide, especially in connection with women's rights, and their status in religion.

By way of introduction, I would like to relate two personal anecdotes. The first concerns an experience from the early 1990s, when I was involved in a committee to establish an Institute for Gender Studies at the University of Calgary and another woman professor came to see me. She was quite upset, even angry with this proposed name. For her, studying "gender" implied merely an appreciation of the socialization process of both men and women. This indicated a definite weakening of feminism from its critical stance, to a more impartial sociological study of the ways by which a culture implements its requisite "masculine" and "feminine" roles. In her understanding, the actual motivations for such cultural impositions, with their stereotypical, if not negative impact on women, would no longer be questioned in such objective gender investigations. A second experience occurred at a conference in 2000. I was stopped by a male scholar who accused me of being a "gender feminist". Though I was aware from his tone that this designation was not a compliment, I was quite perplexed as to the meaning of this term. After a search on the Internet, I learnt that "gender feminism" had now become the contemporary equivalent of the term "women's lib" or "feminist liberation" - a term I was familiar with from my student days. Back in the 1970s and 1980s, these words were used by opponents of feminism to designate the movement as the refuge of man-hating, bra-burning females. 
In these two separate incidents, however, the term "gender" is being used in diametrically opposite ways - firstly as indicating a conservative position, and secondly, a radical one. It fascinates me that such diverse meanings could have come to exist, when, just 35 years ago, "gender" functioned in some languages only as a grammatical indicator. Today, the term continues to be used in a similarly neutral fashion, e.g., the term "gender gap" refers to the phenomenon that more young women than young men attend university in certain faculties. Yet, such a neutral description is not without intriguing political consequences. Books are now being published in the United States with titles such as: "The Plot against Boys" - implying that the education system now favours girls, to the disadvantage of boys, and that this situation needs to be remedied. It would seem that "gender" can never be an unambiguously neutral term again. This fact has prompted my own fascination with the various designations of the word "gender", especially as it relates to Religious Studies. Unfortunately, this essay can only present an overview. Thus my investigations will only highlight the most prominent examples - moving from simple to the more complex illustrations.

\section{Example One: Gender as Equivalent to the Word "Woman"}

Many books can be found that do not explicitly theorize, let alone problematize the concept of "gender". The word is used in a general way that is virtually equivalent to referring to women, as well as to women's roles in society, from a purely descriptive point of view. To give an example, and to show that I am not immune to this tendency, I will cite an article of my own called "God and Gender: Some Reflections on Women's Invocations of the Divine". This appeared in a book edited by Ursula King entitled Gender and Religion (1995). From where I stand now, I can admit that, at that time, I was employing the term without a clear understanding of what the term "gender" meant. It had imprecise connotations that were associated with the qualifier "female", though it was not being used with a necessarily "feminist" intent. 


\section{Example Two: Gender as Indicative of Culturally Accepted Behaviour}

There are other books that understand "gender" as referring to both "male/ masculine" and "female/feminine" roles and characteristics as representative of a society's view of the acceptable behaviour for each sex. Such books indicate an awareness that such roles can change over time, but there is no enquiry into the origin or genealogy of these roles - it is enough to describe them. And maybe, in certain historical studies, this descriptive task is sufficiently demanding to occupy all of the author's attention. As a consequence, however, there is no critical analysis of such conventions. Occasionally such descriptions, whether intentionally or not, do often indicate directions for further judicious enquiry.

An example of this descriptive approach can be found in Patterns of Piety: Women, Gender and Religion in Late Medieval Reformation England (2003) by Christine Peters. It is a study that traces the effects of the Reformation on women, which Peters refers to as the "gender impact" (p. 2). This development is especially evident in the changing practices of piety. Peters depicts a gradual movement after the Reformation towards a more practical Christocentric mode of parish piety, that differed from the former monastic and mystical variety. The seemingly paradoxical view of medieval times where women were simultaneously characterized as more prone to piety, yet also more liable to sin - especially the sins of the flesh - seemed to be fading. Traditional gender stereotypes that characterized men as rational and selfcontrolled, and women as weak and emotional, were also becoming less emphatic. Sin was now being considered in proportion to the degree of responsibility one was accorded within the patriarchal system that still, however, prevailed. Peters observes: "The weak, emotional temptress could be seen as less culpable than both the man who succumbed to her sexual charms, and her husband who had failed his duty to guide and control her. Moreover, that both interpretations were present in varying degrees in late medieval culture added to the ambiguities of gendered experience, as too did the apparently contradictory stereotype of the godly woman." (2003, 346.) Yet, because the book's aim is that of an historical description, there is 
no evaluation of the implications for status of women within what remained a male-dominated religious hierarchy.

\section{Example Three: Gender as Essentialism}

Certain contemporary works have criticized the previous descriptive approach to gender roles in their historical setting. Such works can be appreciated as marking the beginning of an explicit mode of gender criticism. This is because they interrogate the way that "gender" is initially identified with specific cultural attributions or customs that are later advocated as normative - in the sense that they come to represent timeless or essential qualities for women.

In this connection, Kathleen Biddick's essay "Genders, Bodies, Borders: Technologies of the Visible" (1993) is a critique of Carolyn Bynum's book Holy Feast, Holy Fast (1987). Biddick questions both Bynum's notion of the body and her seeming acceptance of the myth of a triumphant Christianitas, with its inevitable elisions and omissions. Bynum's book examined the lives of medieval Christian mystics. In her careful scrutiny, Biddick documents how Bynum's treatment of the "medieval woman saint's body" unproblematically accepts the characterizations of women as reflecting not just an historical, but a pregiven, maternal reality. As Biddick notes: “The model of gender in Holy Feast, Holy Fast assumes that gender is an essence that appears prior to other categories and informs them; that the feminine mirrors, indeed reduces to, the female reproductive function; that the female body is the originary, foundational site of gender" $(1993,397)$.

Biddick's claim is that neither gender nor sex is inherently determinative - indeed, they are both initially imagined and culturally constructed. Rather than taking Bynum's study at face-value, Biddick reads her work as a casestudy of the production of gendered knowledge. As such, it contains specific lessons for today $(1993,390)$. Instead of taking such engendered values as a given which, in Bynum's case, equates a women's body with the maternal, Biddick asks: "How can we write these histories such that in making women 'visible' we do not blind ourselves to the historical processes that defined, 
redefined and engendered the states of the visible and the invisible?" (1993, 390.) In other words, Biddick is concerned with what has been omitted in such an ostensibly realist portrayal. She wonders what Bynum excluded by accepting women's maternity, in both its spiritual and physical sense, as a given, with its all-consuming demands. Biddick's criticism is similar to that of cultural constructivists who, in their turn, subscribe to "the body as blank slate" syndrome. This is a position that views cultural assumptions as simply imposed on a neutral body. One problem that results from this move is that nature (the body) and culture (gender traits) appear to be situated in a binary relationship. A result is that they can easily become mutually exclusive. The consequent theoretical battles between contemporary "essentialists" and "constructivists" have consumed much energy in feminist circles in recent years. Other alternatives, however, have emerged more recently, and I will continue by investigating certain of these options.

\section{Example Four: Gender as a Critical Analytic Category}

Another approach is evident in a volume edited by Kari Elisabeth Børresen, The Image of God: Gender Models in the Judaeo-Christian Traditions (1995). This work is a response to the way in which particular facets of gender have been designated as not simply appropriate or essentialist, but even mandatory for women. The different contributors to this edited volume all evaluate the manner in which the concept of imago dei has been diversely interpreted over the centuries. The notion that has predominated is that it is man alone who is theomorphic, i.e., only the male of the species is made in the image of God. As her main analytical category, Børresen employs the phrase "human genderedness" - which she describes as "the sense of a combined biologically given and a socio-culturally shaped female and male existence" $(1995,1)$. She argues that gender attributions are neither innate nor normative, but culturally influenced. Børresen's principal intention, which is theologically motivated, is to illustrate, through appeal to Christian scripture and tradition, that she understands revelation as a continuous process. Her own interpretation of creation of the sexes appeals to the Biblical pas- 
sage where both male and female are created in the image of God (Gen. 1: 26-28). For Børresen, this passage supports the full inclusion of women in human god-likeness. As a consequence, it is not only men who are to be acclaimed as theomorphic. In this context, Børresen employs gender as an analytic tool of interpretation - but it is an approach that also has critical theological resonances. She supports contemporary claims by women that they be fully accepted as equals within their Christian religious tradition as they are created, both body and soul, in the image of God. From Børresen's perspective, women are thus to be accorded a symbolic status equivalent to that of men.

\section{Example Five: Gender as a Tool of Cultural Analysis}

Two further studies of gender roles and qualities that also regard them as being neither innate nor universal, are anthropological in nature, but fit within the scope of Religious Studies. Both of these investigations add to the growing repertoire of meanings of the term "gender". In her book, Spirited Women: Gender, Religion, and Cultural Identity in the Nepal Himalaya (1996), Joanne Watkins uses the word "gender" in what would initially appear to be a primarily neutral sense. She describes what she terms the "egalitarian gender configurations", i.e., the roles and relations of the Nyeshangte people of Nepal. In this Buddhist society, Watkins portrays the gender relations and roles adopted by men and women as complementary and non-hierarchical. In addition, there occurs what Watkins calls a "gender variance", where the terms "male" and "female" do not subscribe to naturalized or essentialized roles. This indicates for Watkins that certain roles are interchangeable. Within such a setting: "neither men nor women are [...] prevented from participating in their society's two central institutions: international trade and Buddhist ritual practice" (p. 16). Thus, in this society, women perform religious rituals because they are not "denigrated nor are they regarded as polluting" (p. 17). Though Watkins makes no explicit commentary, there nevertheless seems to be an implied comparison with western religious practices, most obviously those of Christianity and Judaism. In these religions it is difficult 
for women to act as ritual specialists, mainly because of the traditionally accepted estimation of menstruation as being unclean or polluting.

Another anthropological study that ostensibly depicts gender in a neutral guise is undertaken by Susan Sered in Women of the Sacred Groves: Divine Priestesses of Okinawa (1999). For Sered, "gender" functions, similarly to Watkins, not as "an immutable fact of life or state of being, but rather [as] an expression of social processes" (p. 7). In her study of Henza society of Okinawa, Japan, Sered finds a "non-hierarchal complementarity - including gender complementarity - as a pervasive pattern in Henza ritual, social life and cosmology" (p. 6). Her specific interest is the priestesses who are the sole ritual officiants for their people and who, in the exercise of their role, become the actual embodiment of the divine presence of the Kami-san (loosely translated as "spirits") - in both their male and female forms (p. 11). In such a society, women could be considered as having a symbolic status equal to men.

Both of these books explicitly describe their understanding of gender as a tool of cultural analysis. Yet while they describe the established cultural patterns of the societies they are investigating, their authors' positions are not entirely neutral. The subtle indictment of western religions evident in the work of Watkins becomes particularly obvious when Sered states: "In the West, gender is understood to be naturally and existentially connected to sex [biology]". Sered views such "naturalization of [gender] differences as a precondition for hierarchy" $(1999,232)$. Her inference is that the west can learn much from societies such as the Henza where the connections between sex and gender are not regarded as automatically natural, and thus do not appear predisposed to ranking the sexes in degrees of spiritual merit.

\section{Example Six: Gender as a Mode of Subversive Disturbance}

The next two examples that I will discuss mark a definite change in approach, particularly because they employ "gender" in both a theoretically sophisticated and critical mode. They have been influenced by the work on gender undertaken by Judith Butler and Joan Scott. These models interrogate accustomed frames of reference that align sex with specific gender 
characteristics that are accepted as natural, if not essentialist, from a religious perspective.

In God, Gender and the Bible (2002), Deborah Sawyer introduces the ideas of Judith Butler, as well as those of the early Luce Irigaray, to disturb traditional gender categories in the Bible. By using Butler's concept of gender as "performative" from Gender Trouble (1990), Sawyer allows that, because prescribed gender behaviour often depends on political ideologies, rather than on any intrinsic characteristics, it can be subverted. Such a strategy depends initially, in Butler's work, on acknowledging the category of gender as performative - that is, as an enactment of roles that can be assumed at will, often with the intent of parodying established norms. This is similar, in some respects, to Luce Irigaray's device of critical mimesis. As a mode of deconstructive reading of philosophic and psychoanalytic texts, this tactic is deployed to reveal the control mechanisms of gendered assignations, especially in their privileging of the male position - be it intellectual, social or religious. (Irigaray 1985, 76.) What both of these approaches advocate is a disturbance of accustomed gendered priorities by a more fluid construction of gender that replaces the traditional binary allocation of male and female to specific roles. Gender becomes a multivalent category, thus liberating sex from its primary identification with the procreative functions of sex. In these models of both the early Butler and early Irigaray, one can ideally - though to my mind, not unproblematically - choose one's gender identity from a spectrum of possibilities.

By arguing that the Bible itself contains the potential for such gender modifications, Sawyer applies this theory to the story of the pious widow, Judith, in the Hebrew Bible. Judith deliberately adopts the wiles of a seductress to first beguile and then decapitate the Assyrian General, Holofernes, an arch-enemy of Israel. Sawyer states: "The chorus of women recognize the achievement of [this] unconventional warrior, and we are able to observe how gender games have been employed to subvert the expected, entrenched norms of this ancient socio-political context" $(2002,97)$. The ultimate irony of this story, however - and this does not escape Sawyer's notice - is the latent message embedded in this text. This warns men to beware of siren women, for it may ultimately cost them their heads. But perhaps the ultim- 
ate irony of such a role reversal is not simply the possibility that God can work in mysterious and unpredictable ways. Unfortunately, in the larger context of the Bible, this particular incident virtually falls into insignificance - overwhelmed by a predominantly male ethos that understands itself as being divinely ordained in the order of creation. There is no doubt in the Hebrew Bible that, insofar as God has a gender, if indeed God has one, it is male. In this tradition, women definitely do not have the same symbolic status as men.

\section{Example Seven: Gender as an Historical Variable}

If such deconstructive mimesis and parodic disturbances can only take us so far - are there other potentially effective strategies in this period when the prefix "post-" has become prolific, and when materialist criticism seems to have lost its momentum? One book that provides further assistance is Playing for Real: Hindu Role Models, Religion and Gender (2004), edited by Jacqueline Suthren Hirst and Lynn Thomas. In surveying certain prescribed role models for Hindu women, whether they appear in sacred texts, myths or popular stories, Hirst and Thomas observe interventions of authority and power latent in these stories, particularly in their directives for proper conduct on the part of women. What is of marked interest to Hirst and Thomas is the social and political contexts that determine these assigned gendered roles. In their "Introduction" to the volume, Hirst and Thomas recognize the complexity of both the reception of and resistance to such role models, inflected as they are in India by caste, age, economic status and political allegiances. Suthren and Hirst acknowledge their theoretical debt for this intricate social analysis to the postcolonial feminist writings of, among others, Rajeswari Sunder Rajan (1993).

Perhaps, however, the most evident influence on their work is that of the American historian, Joan Scott and her theory of gender. Scott, in her work, Gender and the Politics of History (1999 [1988]), depicts the category gender as a critical agent of destabilization. Its intention is one of transformation. To achieve this, Scott believes that the following questions should always 
be asked of a historical text from a critical analytic perspective: "How and under what conditions [have] different roles and functions been defined for each sex; how [have] the very meanings of the categories 'man' and 'woman' varied according to time and place; how [were] regulatory norms of sexual deportment created and enforced; how [have] issues of power and rights played into questions of masculinity and femininity; how [do] symbolic structures affect the lives and practices of ordinary people; how [were] sexual identities forged within and against social prescriptions" $(1999, x i)$. Such a radical programme endeavours to promote investigation of the particular circumstances of all such historical instantiations. In so doing, the hope of Scott, as well as of Hirst and Thomas, is to demonstrate that there can be no ahistorical, let alone "essential" definitions, particularly on matters of sex and gender, insofar as they prescribe ideal behaviour for women.

\section{Reflections on Normativity}

It is this unsettling of gender norms by a strategic deployment of the term "gender", as it has been used by Scott and also Butler, that upset fundamentalist Christians in the United States. It also troubled the late Pope John Paul II as well as neo-conservative elements in other religions, such as Hinduism (Hindutva) and Islam (Islamist). Judith Butler describes her astonishment when she learned of the manoeuvrings of the Vatican in the lead-up to the Beijing conference on the status of women in 1995: "The Vatican not only denounced the term 'gender' as a code for homosexuality, but insisted that the platform language [of the conference] return to the notion of sex, in an apparent effort to secure a link between femininity and maternity as a naturally and divinely ordained necessity" (Butler 2001, 423). Scott herself reports on another occurrence in the United States around the same time, when a sub-committee of the United States' House of Representatives entertained submissions that warned morality and family values were under attack by "gender feminists" (Scott 1999, ix). It would appear that both the Vatican and the neo-conservative groups in the United States had been 
informed of Butler's, if not Scott's, work and their questioning traditional gender roles.

In their depiction of this threatening situation, the opponents of "gender" insisted that "gender feminists" regarded manhood and womanhood, motherhood and fatherhood, heterosexuality, marriage and family as "culturally created, and originated by men to oppress women" (Scott 1999, ix). Nonetheless, in one sense, these foes of gender were perceptive because they did sense that "gender", as it was being used by Butler and Scott, had become, for a time, a key term for women who no longer wished to assume that biology dictated destiny. Legal theorist Drucilla Cornell clarifies this movement: "Gender as an analytic category was the creation of second wave feminism, which came to dispute openly the idea that biological differences between the sexes could ever be used - even affirmatively - to justify women's participation as citizens" (2004, 37). I think that Cornell's distrust of even a positive use of gender difference comes from her suspicion that, all too often, the gender ideals that are affirmatively specified for women do not necessarily respect their bodily or intellectual autonomy.

It is worth noting, however, that the United Nations, in their statements issued after the Beijing conference, reflecting the findings of a special group designated to investigate the usage of the term "gender", did not capitulate to the Vatican's pressure. A motion was passed to the effect that the term "gender" would be retained, in accordance with its accepted usage in numerous other UN forums and documents. The UN declared that there was no indication of any new meaning or connotation of the term "gender" that differed from prior usage. Nevertheless, at this stage of my investigation, one could well ask, what is this ordinary, commonly accepted prior usage of gender that the United Nations accepts? A careful reading of the conference resolutions indicates that "gender" refers to the basic differences between men and women that are taken for granted. It could thus appear that we are right back with a simple neutral descriptive markers - exactly where we started at the beginning of this paper. 
I do not think, however, that the use of the word "gender" as employed by women at the UN is totally innocuous, whether or not this is due to a conscious decision on their part. I make this observation because, in my recent travels in Indonesia and Thailand, I came across two similar instances where the term "gender" was being used in markedly reformative ways. At a conference in Yogyakarta, Java, I chaired a panel on "Feminism in Islam". One of the women participants, who was involved in teaching women's studies at a local college, was using the word "gender" as an effective replacement for the term "feminism". (The latter term is unwelcome in Indonesia because of specific designations of feminism that identify it only with the radical form of western feminism.) In Thailand also, where I interviewed government policy makers, as well as Buddhist nuns, on the situation of women, the word "gender" was also being used in a very deliberate way as an alternative to feminism. In particular, it was being used to argue for "gender balance" in the representation of women in the civil or public service. It also figured prominently in government documents that detailed a programme to combat sexual violence against women. It is obvious that women from these countries, as well as in the UN, have adopted the word "gender" as a substitute, not for radical feminism, but for what, in North America and Europe, would be viewed as the basic liberal feminism of equality.

\section{Global Observations}

Given the extraordinary range of meanings described above that the term gender can designate, one would be perfectly justified in asking exactly where this exploration has got us, apart from some confusion, and even perplexity as to what future direction to take. In fact, there have been a number of negative reactions to this proliferation of meanings. Interestingly, in a recent "Re-Introduction" to a revised version of her book, Gender and the Politics of History (1999), Joan Scott says that she has now given up using the word, because it has lost its radical edge. Other feminists, mainly those in the vanguard of the second wave of feminism, such as Susan Gubar, view it 
as symptomatic of the current diversity within feminism that has caused it to depart from a unified activist position. Gubar is troubled by the present preoccupations with the recognition of multiple forms of difference - be it those of race, class, ethnicity, age, sexual preference - in addition to gender - that are part of a litany that has been labelled, somewhat pejoratively as "identity politics". Gubar describes her misgivings: "By the eighties changes were taking place that laid the groundwork for the third phase of feminist criticism, which I will call the engendering of differences [...] I use the verb 'engendering' for the third stage because it engaged feminists in the activity of bringing gender to bear upon other differences: sexual and racial differences primarily, but also economic, religious, and regional distinctions [...] thereby accentuating dissimilarities among women, divergences among men." (2000, 117.)

Gubar is representative of many second-wave feminists who feel that feminism has today lost its way. She describes this as becoming less focused on what should be its primary goal of improving the living conditions of women, and instead, getting enmeshed in theoretical debates. I am not quite as pessimistic as she is, because although there will still be battles with reactionary forces, the women's movement - under the banner of feminism, or under the guise of "gender" - has gone global in the last thirty years, as many authors have testified (Rupp 1998). To support this contention, I point to the activism of feminism as it has expanded beyond the narrow focus of European and North American women to embrace the experiences of many women from diverse cultures throughout the world. I believe that a strong and informed foundation has been established that facilitates women undertaking activist projects together, particularly on the question of human rights (Agosín 2001). This international movement appears to have gathered strength since the Declaration on the Elimination of Discrimination Against Women's adopted by the United Nations in 1967. In her book, Women, Development and the UN, Devaki Jain details this development, which was often supported by UN agencies led by women: "Women, both inside and outside the UN, no longer attended conferences as members of marginal groups 
or as last-minute additions to conference preparations; their advice and participation was sought from the outset and their leadership in intellectual and policy areas emerged. They used the conferences as platforms to highlight the areas where discrimination and domination still continued. There was a shift here in priorities; a renewal of the recognition, an affirmation of an earlier UNESCO finding that it was through entry into formal power structures that the age-old barriers to equality can be broken." $(2005,104$.)

On the issue of pluralism, especially, and the contribution that it can make to feminist politics, I am in agreement with the views of Susan Bickford. In an article, "Anti-Anti-Identity Politics", she states: "The feminist theorists of race, class gender, and sexuality [...] delve into complicated political meanings. They provide a way of understanding the political dimensions and consequences of group identity [...] one that moves beyond thinking of political identity as an expression of ressentiment, or of group assertion, at the expense of politics." $(1997,118$.) Such complex insights need not imply that on all issues there will be complete agreement by women who come from quite disparate national and international backgrounds. Nonetheless, especially in the work at the UN over the past three decades, I detect a growing groundswell of global awareness, particularly of the injustices that continue to be perpetrated against women in the manifold cultures and religions of the world. This increasing cooperation has allowed for concerted efforts on a number of fronts, in particular that of violence against women. As Charlotte Bunch has observed:

As a human rights issue, the effort to end violence against women becomes a government's obligation, not just a good idea. This means that women can work to hold governments at all levels accountable for their failure to meet this obligation. In this effort, women have gained access to a variety of mechanisms (national, regional and international) used by the human rights community in the effort to expose human rights abuses and to hold governments accountable to their obligations. These gains include the appointment of a UN Special Rapporteur on Violence Against Women, the adoption of the Inter-American Convention on Violence, the Women's Protocol to the African Convention on Human Rights, the inclusion of sexual violence 
and gender-based persecution in the statuses of the International Criminal Court. $(2004,1$.

\section{Subverting Essentialisms}

Such developments have brought about extremely significant changes in the thinking of theorists from the developed world, such as Judith Butler. Despite the fact that she is still regarded as the figurehead of the polymorphous play of gender-bending, Butler has recognized the need for concerted political action on the part of women in response to recent reactionary political manoeuvres at the UN. She recently stated: "Although many feminists have come to the conclusion that the universal is always a cover for a certain epistemological imperialism, insensitive to cultural texture and difference, the rhetorical power of claiming universality for say, rights of sexual autonomy and related rights of sexual orientation within the international human rights domain appears indisputable" $(2001,423)$. This is in keeping with certain developments in her thinking since Gender Trouble (1990). In both Bodies that Matter (1993) and another later interview "The End of Sexual Difference" (2001), Butler has acknowledged that initially she may have played too fast and loose with gender as performance, at the expense of recognizing certain claims of the physical body and its protection from abuse. She does admit, however, that gender will remain a contentious site, in that gender norms have functioned, and will continue to function, in many societies, not simply as regulative, but as fixed and non-negotiable items (2001, 427).

Butler's political strategy can be compared with that of Uma Narayan, a scholar who is originally from India, but now teaches in the United States. In two publications, Dislocating Cultures: Identities, Traditions and Third World Feminism (1997), and "Essence of Culture and a Sense of History" (1998), Narayan discusses the problem of "cultural imperialism" by comparing it to "gender essentialism". Introducing yet another understanding of the word "gender", she states: "While gender essentialism often equates the problems, interests, and locations of some socially dominant groups of men and 
women with those of 'all men' and 'all women', cultural essentialism often equates the values, worldviews and practices of some socially dominant groups with those of 'all members of the culture'" $(1998,88)$. To counter such cultural essentialism, Narayan suggests a process of "cultural analysis" that is similar to Joan Smith's critical "gender analysis". In analyzing the specific example of sati - the immolation of widows - a practice which is often slated by western women as an example of Hindu women's collective subjugation, Narayan recommends an informed historical understanding of the contextual pressures, particularly religious and political ones, in the promotion of a pan-Indian womanhood. She refers to the complex nineteenth-century debates that took place in colonized India between Indian elites and the British colonialists that resulted in establishing sati as a "central and authentic tradition" $(1998,93)$, whereas previously it had been confined to specific castes and geographical regions. Narayan's discussion helps to situate the contemporary outcome: "This colonial history helps explain why sati has become a politically salient symbol of 'Indian culture' available for deployment by Hindu fundamentalists today" (p. 94). A "manufactured" essentialism is thus demonstrated as playing into the hands of contemporary nationalists who endorse a return to a former halcyon era, especially as existed for women during early Vedic times.

This false nostalgia, which has marked religious associations, has also been criticized by other Indian women scholars, notably by Uma Chakravarti in "Whatever Happened to the Vedic Dasi" (1989), and by Kumkum Roy's in her ironically titled essay: "Where Women are Worshipped, There the Gods Rejoice" (1995). These essays support Narayan's own argument against any form of cultural essentialism. Narayan then draws a parallel conclusion by stating that just as there is no one essential description of the female gender, there is no authentic cultural identity. In expanding this position, Narayan's will finally reject not only "the idea that there is anything that can solidly and uncontroversially be defined as 'Indian culture', but also the idea of an 'African culture' or [for that matter] 'Western culture'”' $(1998,102)$. 


\section{The Pros and Cons of Generalizations}

At the same time as Narayan argues against essentialisms of gender and culture, she nevertheless appreciates the value of generalizations. This is an observation of utmost importance, because one of the primary accusations against the type of critical gender analyses undertaken by Butler and Scott, or the cultural analysis of Narayan, is that they undermine the formation of any universals. But this is not necessarily the case as, so often in these accusations, generalizations as universals are mistakenly identified with essentialism. Such an inaccuracy can impede any collective activism on the part of women to improve their situations. This is why Narayan's observations are crucial. She declares: "The claim that virtually every community is structured by relationships of gender that comprise specific forms of social, sexual and economic [and religious] subjection of women seems a generalization that is politically useful; it also leaves room for attention to differences and particularities of context with respect to the predicaments of different groups of women" $(1998,103)$.

The type of strategic generalization that Narayan is supporting here is extremely similar to Butler's earlier quoted statement concerning the applicability of universals, with contextually considered qualifications, to claims for women's rights. The fact that two women such as Butler and Narayan, coming from very different backgrounds, who are both very careful in their use of words, support such tactical use of generalizations, is remarkable. I believe that they both have come to realize the repercussions of a major backlash that is being undertaken by fundamentalist religions against the rights that women have won. This became particularly evident for Butler when the Vatican intervened at the UN on the issue of "gender feminism". Since that time it has attempted to influence members of the Catholic communities from a number of developing countries (especially in Central and South America [Guzmán Stein 2001]), as well as Islamic countries, to support its own position (Baynes \& Tohidi 2001). Part of its tactic is to argue that human rights for women, especially in the context of gender, is a "western", i.e., colonialist, imposition. This alignment by the Vatican with the colonized 
and underprivileged of this world, as well as with non-exploitative interests, is patently disingenuous. It is simply another example of the manner in which it has orchestrated, often with the help of ruling regional elites, a blatant appropriation and deployment of gendered idealizations. These traditional formulas are designed to keep women in their proper maternal place, as the unsullied guardians of a nation's morality.

Such a manipulation of history, in order to promote a glorious past, from which contemporary society has sadly fallen, and which needs to be reestablished, is a hallmark of many fundamentalist religious movements. It is both sad and extremely telling that, in many of these religions, the cause of a nation's fall from grace is blamed on women's waywardness, especially sexual deviance. As a result, women need to be rescued from their fallen ways and returned to supervision and subservience. Gender, insofar as it enters into these calculations, features as a divinely ordained decree. Both men and women are directed, under pain of sin or a bad rebirth, to follow the gendered scripts that provide the rigid backbone of a stable, god-fearing society. From this viewpoint, women's increasing demands for self-determination are decried as nothing less than selfish self-fulfillment. The struggles against expanding women's rights since the Beijing conference on various UN committees, especially apparent in the recent failure by signatory nations to pass a resolution on the implementation of the Declaration of Elimination of Violence against Women, ostensibly on the grounds of protecting religious traditions (Freeburg 2003), are evidence of this reactionary mind-set. In this way, as is blatantly obvious in the contemporary United States, but also in other religions and countries of the world, the battle lines are being definitively drawn by fundamentalists and neo-conservatives (Howland 1999). Some scholars are wondering if it is even worth continuing the struggle for women's rights at the UN, so effectively organized has the opposition become (Posadskaya-Vanderbeck 2004). 


\section{Conclusion}

It is in this context of deepening hostility that I want to take stock of the variant uses of the word "gender" and assess what insights the analyses that I have undertaken can supply. In addition, I would like to draw some conclusions that can be relevant for contemporary women - that is, if they no longer wish to subscribe to rules and regulations that are unjustly imposed on them in the name of religion, and if they do not accept that their arguments for freedom of choice and autonomy contribute to the impending collapse of their nation's moral integrity.

It is now time to bring together the various threads that have been weaving their way through my presentation, ostensibly on gender and religion, but with much wider reverberations. The position that I want to finally defend, with regard to women's rights, specifically with reference to gender and religion, is one where women no longer accept that their roles are divinely mandated - however that is expressed in diverse religions and cultures. I will concede that it is not possible to arrive at a formulation of the word "gender" that will take into account all its variant meanings, but I do not believe this is necessary. As a rhetorical device, gender has served its purpose to illustrate a number of extremely cogent ideas. No matter the meaning assigned to the word "gender", it is a term that has provided, and can continue to provide, if astutely applied, a means of expression that is both critical and constructive. In employing the word "gender", women as diverse as Joan Scott, as the women in the United Nations, and the women scholars and workers that I met in Indonesia and Thailand - women in both academia and public realm - all have learnt something extremely valuable. This is that, in their analysis of societal controls, such women have begun to appreciate the ways in which their traditional positions of inferiority and/or exclusions were embedded in a matrix of forces - at once religious, political, economic, and legal - to name just a few of the most prominent influences. The tool of "gender analysis" has enabled them to disentangle many of the mutually reinforcing elements of this matrix and to begin to formulate appropriate strategies to counter their effects. There needs to 
be a suspicion of all forms of enculturated ideals of identity which appeal to essences - be it of women, "femininity", glorious pasts, "First World", "Third World", or any religious stereotypes that target difference as alien or defective. There also needs to be a realistic, if not skeptical, awareness of the ways that such constructed identities continue to be promoted and exploited by agencies such as fundamentalist religions. This task will require both sensibility and wisdom. For I am deeply concerned that the future battlefield is going to include religion, but here I am not referring to the so-called clash of civilizations between the powers of the Christian West and Islam. I think that the battle will be closer to home, and I have a gut feeling - which I hope is wrong - that the role of women may well be at the centre of this struggle.

Uma Narayan has declared that " $[\mathrm{m}]$ any religious traditions are in fact more capacious than fundamentalist adherents allow. Insisting on humane and inclusive interpretations of religious traditions might, in many contexts, be crucial components in countering the deployment of religious discourses to problematic nationalist ends." (1997, 35.) I would like to suggest that women scholars in Religious Studies are uniquely situated and singularly well-equipped to respond to this challenge, not just with regard to nationalism, but to any "-isms" of a fundamentalist variety. Their training supplies them with the knowledge and the method to call to account any spurious claims to precedent, as well as textual readings that are either selective or literalist in their applications. I hope that we will be equal to the task. 
Bibliography

\section{Agosín, Marjorie}

2001 Women, Gender, and Human Rights. New Brunswick NJ: Rutgers University Press.

\section{Baynes, Jane H. \& Nayereh Tohidi}

2001 Introduction. - Jane H. Baynes \& Nayereh Tohiri (eds), Globalization, Gender and Religion. The Politics of Women's Rights in Catholic and Muslim Contexts, 1-15. New York: Palgrave.

\section{Bickford, Susan}

1997 Anti-Anti-Identity Politics: Feminism, Democracy, and the Complexities of Citizenship. - Hypatia 12(4), 11-131.

\section{Biddick, Kathleen}

1993 Genders, Bodies, Borders: Technologies of the Visible. - Speculum 68, 389-418.

\section{Børresen, Elisabeth}

1995 The Image of God: Gender Models in Judaeo-Christian Tradition. Minneapolis: Fortress Press.

\section{Bunch, Charlotte}

2004 What are the Implications of a Rights Based Approach for the Struggle against Violence against Women? An Interview with Charlotte Bunch. -Women's Human Rights net [http://www.whrnet.org/docs/interviewbunch-0402.html].

\section{Butler, Judith}

1990 Gender Trouble: Feminism and the Subversion of Identity. New York: Routledge.

1993 Bodies that Matter: On the Discursive Limits of "Sex". New York: Routledge.

2001 The End of Sexual Difference? - Elisabeth Bronfen \& Misha Kavka (eds), Feminist Consequences: Theory for the New Century, 414-434. New York: Columbia University Press.

\section{Bynum, Caroline Walker}

1987 Holy Feast, Holy Fast: The Religious Significance of Food to Western Women. Berkeley: University of California Press.

\section{Chakravarti, Uma}

1989 Whatever Happened to the Vedic Dasi? Orientalism, Nationalism and a Script from the Past. - Kumkum Sangari \& Sudesh Vaid (eds), Recasting Women: Essays in Colonial History, 27-87. New Delhi: Kali for Women. 


\section{Cornell, Drucilla}

2004 Defending Ideals: War, Democracy, and Political Struggles. New York: Routledge.

\section{Freeburg, Emily}

2003 U.N. Pact Sinks on Issue of Violence Against Women. - Womens's eNews [http://www.womensenews.org/article.cfm/dyn/aid/1304].

\section{Gubar, Susan}

2000 Critical Condition: Feminism at the Turn of the Century. New York: Columbia University Press.

\section{Guzmán Stein, Laura}

2001 The Politics of Implementing Women's Rights in Catholic Countries of Latin America. - Jane H. Baynes \& Nayereh Tohiri (eds), Globalization, Gender and Religion. The Politics of Women's Rights in Catholic and Muslim Contexts, 127-155. New York: Palgrave.

\section{Hirst, Jacqueline Suthren \& Lynn Thomas (eds)}

2004 Playing for Real: Hindu Role Models, Religion, and Gender. Oxford: Oxford University Press.

\section{Howland, Courtney W. (ed.)}

1999 Religious Fundamentalisms and the Human Rights of Women. New York: St. Martin's Press.

\section{Irigaray, Luce}

1985 This Sex Which Is Not One. C. Porter \& C. Burke (trans). Ithaca: Cornell University Press.

\section{Jain, Devaki}

2005 Women, Development, and the UN: A Sixty-Year Quest for Equality and Justice. Bloomington IN: Indiana University Press.

Joy, Morny

1995 God and Gender: Some Reflections on Women's Invocations of the Divine. - Ursula King (ed.), Religion and Gender, 121-143. Oxford: Blackwell.

\section{Li, Xiao-Jian}

2004 Xingbie or Gender. - Nadia Tazi (ed.) Gender. For a Different Kind of Globalization (Keywords Series, Volume 3), 87-102. New York: Other Press.

\section{Narayan, Uma}

1997 Dislocating Cultures: Identities, Traditions, and Third World Feminism. New York: Routledge. 
1998 Essence of Culture and a Sense of History: A Feminist Critique of Cultural Essentialism. - Hypatia, 13(2), 86-106.

\section{Peters, Christine}

2003 Patterns of Piety: Women, Gender and Religion in Late Medieval and Reformation England. Cambridge: Cambridge University Press.

Posadskaya-Vanderbeck, Anastasia

2004 International and Post-socialist Women's Rights Advocacy: Points of Convergence and Tension. - Joanna Kerr \& E. Sprenger \& A. Symington (eds), The Future of Women's Rights: Global Visions \& Strategies, 186-196. London: Zed Books.

Rajan, Rajeswari Sunder

1993 Real and Imagined Women: Gender, Culture and Postcolonization. New York: Routledge.

\section{Roy, Kumkum}

1995 "Where Women are Worshipped, There the Gods Rejoice": The Mirage of the Ancestress of the Hindu Woman. - Tanika Sarkar \& Urvashi Butalia (eds), Women and Right-Wing Movements: Indian Experiences, 10-28. London: Zed Books.

\section{Rupp, Leila J.}

1998 Worlds of Women: The Making of an International Women's Movement. Princeton NJ: Princeton University Press.

\section{Sawyer, Deborah}

2002 God, Gender and the Bible. London: Routledge.

\section{Scott, Joan Wallach}

1999 [1988] Gender and the Politics of History. New York: Columbia University Press.

\section{Sered, Susan}

1999 Women of the Sacred Groves: Divine Priestesses of Okinawa. New York: Oxford University Press.

Watkins, Joanne C.

1996 Spirited Women: Gender, Religion, and Cultural Identity in the Nepal Himalaya. New York: Columbia University Press. 